\title{
Racial/ethnic and educational inequities in restrictive abortion policy variation and adverse birth outcomes in the United States
}

Sara K. Redd ${ }^{1,2^{*}}$ (D) Whitney S. Rice ${ }^{2,3}$, Monica S. Aswani $^{4}$, Sarah Blake ${ }^{1,2}, Z_{\text {Zeë Julian }}^{5}$, Bisakha Sen ${ }^{6}$, Martha Wingate ${ }^{6}$ and Kelli Stidham Hall ${ }^{2,3,7}$

\begin{abstract}
Background: To examine racial/ethnic and educational inequities in the relationship between state-level restrictive abortion policies and adverse birth outcomes from 2005 to 2015 in the United States.

Methods: Using a state-level abortion restrictiveness index comprised of 18 restrictive abortion policies, we conducted a retrospective longitudinal analysis examining whether race/ethnicity and education level moderated the relationship between the restrictiveness index and individual-level probabilities of preterm birth (PTB) and low birthweight (LBW). Data were obtained from the 2005-2015 National Center for Health Statistics Period Linked Live Birth-Infant Death Files and analyzed with linear probability models adjusted for individual- and state-level characteristics and state and year fixed-effects.

Results: Among 2,250,000 live births, 269,253 (12.0\%) were PTBs and 182,960 (8.1\%) were LBW. On average, states had approximately seven restrictive abortion policies enacted from 2005 to 2015. Black individuals experienced increased probability of PTB with additional exposure to restrictive abortion policies compared to non-Black individuals. Similarly, those with less than a college degree experienced increased probability of LBW with additional exposure to restrictive abortion policies compared to college graduates. For all analyses, inequities worsened as state environments grew increasingly restrictive.

Conclusion: Findings demonstrate that Black individuals at all educational levels and those with fewer years of education disproportionately experienced adverse birth outcomes associated with restrictive abortion policies. Restrictive abortion policies may compound existing racial/ethnic, socioeconomic, and intersecting racial/ethnic and socioeconomic perinatal and infant health inequities.
\end{abstract}

Keywords: Abortion, Health policy, Health services research, Reproductive health services, Adverse birth outcomes, US state laws, Race/ethnicity, Education, Health disparities, Health inequities

\footnotetext{
* Correspondence: skredd@emory.edu

'Department of Health Policy and Management, Rollins School of Public Health, Emory University, 1518 Clifton Rd NE, Atlanta, GA 30322, USA

${ }^{2}$ Center for Reproductive Health Research in the Southeast (RISE), Emory University, 1518 Clifton Rd NE, Atlanta, GA 30322, USA

Full list of author information is available at the end of the article
}

(c) The Author(s). 2021 Open Access This article is licensed under a Creative Commons Attribution 4.0 International License, which permits use, sharing, adaptation, distribution and reproduction in any medium or format, as long as you give appropriate credit to the original author(s) and the source, provide a link to the Creative Commons licence, and indicate if changes were made. The images or other third party material in this article are included in the article's Creative Commons licence, unless indicated otherwise in a credit line to the material. If material is not included in the article's Creative Commons licence and your intended use is not permitted by statutory regulation or exceeds the permitted use, you will need to obtain permission directly from the copyright holder. To view a copy of this licence, visit http://creativecommons.org/licenses/by/4.0/ The Creative Commons Public Domain Dedication waiver (http://creativecommons.org/publicdomain/zero/1.0/) applies to the data made available in this article, unless otherwise stated in a credit line to the data. 


\section{Background}

Over the last decade, states have enacted a variety of restrictive abortion policies at a rapidly increasing rate [13]. Since 2011, nearly 500 abortion restrictions have been enacted in states around the U. S [4], increasing the hostility of state environments towards abortion access. According to the Guttmacher Institute, over half of states are hostile to abortion rights, and $58 \%$ of women aged 15-44 reside in states considered hostile or very hostile to abortion services, meaning states had four or five (hostile), or six (very hostile) restrictive abortion policies in place [2]. Existing literature examining the implications of restrictive abortion policies have found associations between restrictive abortion policies and pregnant people planning to continue a pregnancy (versus seeking abortion) [5], decreased abortion rates [616], delayed abortions [9, 17-21], reduced provider availability [9, 10, 22-25], and increased financial and logistic barriers to care [26-32].

The increased implementation of state policies reducing access to abortion services limits the reproductive autonomy [33, 34] of those capable of pregnancy and has important implications for the health and wellbeing of these individuals and their children. As structural determinants of health [35] that shape who and via what means pregnant people can access abortion, pregnant people living in restrictive sociopolitical environments who are unable to access abortion services may end up continuing their pregnancy [5], resulting in adverse birth outcomes via a number of potential mechanisms. Because pregnancy and childbirth are inherently more dangerous and associated with more pregnancy-related morbidities and mortality than legal induced abortion, individuals unable to access abortion may be at increased risk for adverse birth outcomes [36-40]. Additionally, states with legal environments that restrict abortion access often lack supportive policies promoting the health and safety of pregnant people, their children, and their families - such as Medicaid expansion, expansive family/medical leave, and comprehensive sex education $[41,42]$ - which may result in reduced access to supportive services and thus contribute to adverse birth outcomes [33, 34, 42, 43]. Lastly, being unable to access desired medical care - in tandem with navigating structural barriers to obstetric care (e.g., lack of insurance coverage, documented shortages of obstetric providers [35]) and living in the historical and contemporary context of the United States - may increase psychosocial stress for the pregnant person, thus increasing their risk for adverse birth outcomes [44-47]. Indeed, research has linked restrictive abortion policies to increased rates of infant and maternal mortality, low birthweight, and child fatality and homicide deaths [47-54], and findings from our previous analysis suggest that increases in restrictive abortion policies were associated with increased probabilities of preterm birth and low birthweight in the Midwestern, Northeastern, and Western regions of the U.S. (Redd, et al. [2021]. Variation in Restrictive Abortion Policies and Adverse Birth Outcomes in the United States from 2005 to 2015, in press).

A substantial body of theory and literature has demonstrated the integral role that structural determinants, including health policy, play in influencing health and reinforcing health inequities [35, 55-58]. The United States has a rich history of enacting racist and classist policies at the federal and state level that explicitly or implicitly target, endanger, and even criminalize the fertility, sexuality, and reproduction of Black, Indigenous, immigrant, and lower-income populations [33-35, 59]. Indeed, restrictive abortion policies have become a critical macro-level factor shaping access to abortion care in the United States $[42,60]$ that inherently devalues the health and wellbeing of pregnant people. Research suggests that sociodemographic inequities [61-64] in abortion care are driven by structural factors [57] outside of an individual's control, including decreased access to health care (including contraceptive services), provider availability, restrictions of insurance coverage of abortion, residential segregation, and economic disadvantage $[61,65,66]$. Given the persistent sociopolitical context surrounding reproductive policies in the U.S., and because people of color - particularly Black individuals and those with lower socioeconomic statuses (SES) access abortion services at higher rates [63], restrictive abortion policies are likely to disproportionately affect these populations [67] and unduly influence health outcomes for pregnant people and their infants.

A handful of studies have demonstrated that restrictive abortion policies (or other policies governing reproductive rights) are associated with decreased access to abortion care for people of color and those with lower SES $[67,68]$ and increased risks of unintended teen births [69] and low birthweight among Black women [53]. Given the landscape of racial/ethnic and socioeconomic inequities in birth outcomes in the U.S. [70-86], policies restricting access to abortion have the potential to exacerbate adverse birth outcomes, as well as inequities in said outcomes, for people of color and those with lower SES. Furthermore, inequities in birth outcomes are intersectional [87]. Although higher education levels may be protective of adverse birth outcomes, numerous studies have demonstrated that, even among the highest educated groups, racial/ethnic inequities in birth outcomes persist, with Black individuals having the poorest health outcomes [88-93]. To our knowledge, few studies from the abortion policy literature base have explicitly examined how sociodemographic factors moderate the associations of restrictive abortion policies on adverse birth 
outcomes, resulting in a substantial conceptual gap in the field. As such, the objective of our paper was to assess whether the relationship between restrictive abortion policies and adverse birth outcomes was moderated by race/ethnicity and education level.

\section{Methods}

In this analysis, we used linear probability modeling to determine if the relationship between state-level restrictive abortion policies and two individual-level adverse birth outcomes - preterm birth (PTB) and low birthweight $(\mathrm{LBW})$ - varied for people of different racial/ethnic identities and education levels, from January 1, 2005 to December 31, 2015 in the United States.

\section{Data sources and measures}

\section{Outcomes}

We defined PTBs as births occurring before 37 weeks gestation [94] and employed a binary $1 / 0$ indicator for birth prior to 37 weeks versus 37 weeks or after. We classified births as LBW when less than $2500 \mathrm{~g}$ [94] and employed a binary $1 / 0$ indicator for infant birthweight of less than $2500 \mathrm{~g}$ versus $2500 \mathrm{~g}$ or more. We obtained outcome data from the National Center for Health Statistics (NCHS) Period Linked Live Birth-Infant Death Files [95], which contain births occurring in all states and Washington, D.C., from 2005 through 2015.

\section{Exposure: state-level restrictiveness index}

Given the substantial increase in implementation of state-level policies restricting abortion across over the last decade, the abortion policy landscape is complex, highly varied, and difficult to evaluate quantitatively. In an effort to understand implications of the widely varying abortion policy environments, we sought to capture the restrictiveness of state environments towards abortion by creating an additive measure of enacted state restrictive abortion policies. We created and examined a composite state-level index of 18 restrictive abortion policies reducing abortion access and provision, using data from the National Association for the Repeal of Abortion Laws (NARAL) Pro-Choice America's State Government Law and Policy databases [96] and Temple University's Abortion Law Project [97]. We included the following restrictive abortion policies in our restrictiveness index: 1) abortion facility licensing requirements; 2 ) bans on insurance coverage of abortion for state employees; 3) bans on insurance coverage of abortion in health exchange plans; 4) bans on insurance coverage of abortion in all private insurance plans; 5) bans on public funding of abortion; 6) gestational age limits; 7) hospitalization requirements; 8) medication abortion administration only by licensed physician; 9) medication abortion administration in physical presence of patient;
10) mandatory counseling requirements; 11) mandatory ultrasound requirements; 12) mandatory waiting period requirements; 13) "partial-birth" abortion bans; 14) parental involvement laws; 15) abortion provision only by licensed physician; 16) physician hospital admitting privilege requirements; 17) provider refusal clauses; and 18) second physician requirements.

We coded policies as dichotomous beginning with the year the policy was enacted, with a " 1 " indicating that a policy was is in effect in a given state and year and a "0" indicating it was not. We included enjoined policies in the index, as policy enactment may still influence provider and patient behavior regardless of injunction status [98], until ruled unconstitutional. For instance, Alabama's House Bill 57 [99] included a physician hospital admitting privilege requirement which was enacted in 2013, enjoined in 2013, and ruled unconstitutional in 2014. Using these inclusion criteria, we included this admitting privilege requirement in the index in 2013 and excluded it in 2014. We then summed the number of policies in each state and year - each policy counting separately - into a count variable. Thus, the final exposure measure was a state-level restrictiveness index aggregating the number of enacted restrictive abortion policies in a given state during a given year, with higher numbers representing greater restriction. The minimum number of policies a state may have in a given year was zero, and the maximum 18. Because policies enacted in a given year are not likely to affect infant outcomes until the subsequent year given the nine-month gestation period, we lagged the restrictiveness index by 1 year.

Lastly, as this index does not have a meaningful scale per se, we standardized the restrictiveness index in regression models in order to improve interpretation of this measure. Using this standardized measure, a value of zero represents the average number of restrictive abortion policies in the sample (approximately seven policies), and a one-unit change in the restrictiveness index represents a one standard deviation change (approximately four policies) in the index. Thus, we interpreted parameter estimates as changes given a onestandard deviation (SD), or four-policy, increase in the restrictiveness index. Additionally, we inspect predictive margins and average marginal effects of our analyses to probe how the relationship between race/ethnicity or education levels and our outcomes change across a range of values of restrictiveness index values.

\section{Moderators: individual-level race/ethnicity and education}

We investigate the potential moderating effect (i.e., interaction effects) of a birthing person's race/ethnicity and education level, data which are derived from the NCHS dataset. Since these factors may lead to heterogeneity in the relationship between state-level abortion 
policies and adverse birth outcomes, simply controlling for them would not allow us to identify and understand inequities in birth outcomes along these dimensions. We operationalized a birthing person's race/ethnicity in two ways. First, we employed a five-level categorical variable: American Indian/Alaska Native (AIAN) (non-Hispanic), Asian American/Pacific Islander (AAPI) (non-Hispanic), Black (non-Hispanic), Hispanic or Latinx, and White (non-Hispanic). Second, because the most substantial racial/ethnic inequities in birth outcomes are observed between Black and non-Black infants [75, 78, 80, 81, 83, $84,86]$ and because Black individuals are disproportionately negatively impacted by structural determinants shaping access to health-promoting resources [35, 100], we employed a dichotomous $1 / 0$ variable indicating whether a pregnant person identified as Black or nonBlack (i.e., AIAN, AAPI, Hispanic or Latinx, and White). Regarding education level, we employed a four-level categorical variable: less than high school graduate, high school graduate or obtained GED, attended some college, and college graduate or beyond.

\section{Covariates}

We controlled for individual- and time-varying statelevel demographic, economic, and political characteristics. In this analysis, "individual-level" refers to a unique parent-infant pair but is subsequently referred to as individual for simplicity. Individual-level covariate data came from the NCHS dataset and included birthing parent sociodemographic characteristics (i.e., age, marital status) and health risk factors (i.e., number of births and prenatal care visits, diabetes, chronic hypertension, pregnancy-associated hypertension, eclampsia) and infant characteristics (i.e., sex and plurality). State-level covariate data came from a variety of sources (e.g., American Community Survey, Bureau of Labor Statistics, Current Population Survey, Guttmacher Institute, National Center for Health Statistics, and the National Conference of State Legislatures) and included demographic (i.e., percentage of population that were at least high school graduates, married, and identified as people of color), economic (i.e., poverty, uninsured, and unemployment rates), and political and policy characteristics (i.e., state legislature composition, average monthly Temporary Assistance for Needy Families benefits [adjusted to 2010 dollars], Medicaid expansion, and Medicaid family planning expansion).

\section{Descriptive analysis}

To identify inequities in adverse birth outcomes and exposure to restrictive abortion policies differed, we first conducted bivariate descriptive statistics using Pearson $X^{2}$ and one-way analysis of variance (ANOVA) tests.

\section{Main analysis}

We investigate if the relationship between state-level restrictive abortion policies and individual-level probabilities of PTB and LBW differed by a person's race/ ethnicity and education level. We estimated the following general form of multivariate linear probability model [101] using state and year fixed-effects (FEs) [102]:

$$
\begin{aligned}
Y_{i s t}= & \beta_{0}+\beta_{1} R I_{s(t-1)}+\beta_{2} M_{i s t}+\beta_{3} R I_{s(t-1)} * M_{i s t} \\
& +\beta_{4} X_{1 i s t}+\beta_{5} X_{2 s t}+\rho_{s}+\tau_{t}+\varepsilon_{i s t}
\end{aligned}
$$

In Eq. 1, ${ }_{i}$ denotes an individual, ${ }_{s}$ denotes the state, and ${ }_{t}$ denotes the year. $Y_{\text {ist }}$ represents the outcomes. $R I_{s(t-1)}$ represents the standardized lagged restrictiveness index, or the number of restrictive abortion policies in effect in a state $s$ during the previous year $(t-1) . M_{i s t}$ represents the moderator of interest (i.e., race/ethnicity or education), and $R I_{s(t-1)} * M_{s t}$ represents the interaction between the restrictiveness index and the moderating variable. This interaction term $\left(\beta_{3}\right)$ is our primary parameter of interest. $X_{\text {list }}$ is the vector of individual-level covariates, and $X_{2 s t}$ is the full vector of state-level covariates. $\rho_{s}$ denotes state FEs accounting for time-invariant heterogeneity across states, while $\tau_{t}$ denotes year FEs accounting for national secular trends in the outcomes. $\varepsilon_{i s t}$ represents the error term.

We clustered standard errors at the state level in order to account for serial correlation of observations within states [103]. We opted to use linear probability models, rather than logit models, for improved efficiency and interpretability given the size of the sample and our inclusion of interaction terms and fixed effects. We, used Wald tests to examine the statistical significance of the interaction terms. For brevity, we only present and describe results from the interaction terms (including Wald tests) in each analysis (Table 2); results from full regression models are presented in Supplemental Tables 1, 2, and 3. Using estimates from the linear probability regression models, we provide predictive margins of both outcomes at various levels of the restrictiveness index ( 1 standard deviation [SD] to $+2 \mathrm{SD}$ ) for all racial/ethnic and educational subgroups in Table 3. Although not presented here, we further investigated the potential for moderation of the relationship between restrictive abortion policies and adverse birth outcomes by race/ethnicity and education via a three-way interaction (see Supplemental Tables 4, 5, 6 and Supplemental Figs. 4, 5, 6, and 7).

Additionally, we provide graphical interaction plots for models with significant interaction terms. ${ }^{1}$ The first set of plots display predictive margins of a given model, representing the predicted effect of the restrictiveness

${ }^{1}$ Interaction plots for models with non-significant interaction terms are presented in Supplemental Figures 1, 2, and 3. 
index on the probability of the outcome for individuals in each moderator category, controlling for all other covariates in the model. The second set of plots display average marginal effects for a given model, representing the predicted effect of the restrictiveness index on the probability of the outcome if values of the moderator are changed (e.g., comparing a specific group to the reference group), controlling for all other covariates in the model. For all plots, the $\mathrm{x}$-axis (standardized lagged restrictiveness index) spans from $-2 \mathrm{SD}$ to $+3 \mathrm{SD}$; this represents the approximate range of the standardized restrictiveness index in all states during the study period (actual values: $-1.71 \mathrm{SD}$ to $2.53 \mathrm{SD}$ ).

Due to capacity issues caused by the large number of observations in the NCHS dataset $(N=44,992,972)$ and our modeling strategy, we drew a $5 \%$ state-year stratified random sample using proportional allocation, resulting in a final sample consisting of 2,250,000 births. To assess robustness of results, we repeated this sampling procedure twice with replacement; results were consistent across samples. We conducted all data management and analyses using SAS 9.4 and Stata/SE 16.0.

\section{Results}

\section{Descriptive analysis}

As shown in Table 1, across the study period, states had an average of seven restrictive abortion policies enacted, $12.0 \%$ of births were preterm, and $8.1 \%$ were low birthweight. Black individuals lived in states with the most enacted restrictive abortion policies (7.4), while AAPI and Hispanic/Latinx individuals lived in states with the fewest enacted restrictive abortion policies (4.6 and 5.3, respectively). In terms of adverse birth outcomes, Black individuals had the highest rates of PTB (17.2\%) and LBW (13.5\%), while AAPI and White individuals had the lowest rates of PTB (10.4 and 10.8\%, respectively) and Hispanic/Latinx, White, and AIAN individuals had the lowest rates of LBW (7.0, 7.2, and $7.3 \%$, respectively). Although the relationship between individual education levels and state restrictive abortion policies was statistically significant, there were no clear trends around exposure to restrictive abortion policies. However, rates of infant morbidity declined with increasing education levels; rates of PTB and LBW were highest among individuals with less than a high school education (13.8 and 9.1\%) and lowest among college graduates (10.0 and 6.9\%).

\section{Linear probability regression models}

Table 2 presents results from linear probability models examining the moderating effect of race/ethnicity (Sections $\mathrm{A}$ and $\mathrm{B}$ ) and education (Section $\mathrm{C}$ ) on the relationship between a state's standardized restrictiveness index and the probability of PTB (column 1) and LBW (column 2).

Table 1 Exposure to Restrictive Abortion Policies and Probability of Preterm Birth and Low Birthweight by Race/Ethnicity and Education Level: Period Linked Live Birth-Infant Death Files, 2005-2015 ( $N=2,250,000)$

\begin{tabular}{|c|c|c|c|}
\hline & \multicolumn{3}{|l|}{ No. $(\%)$ or Mean \pm SD } \\
\hline & Lagged Restrictiveness Index & Preterm Birth & Low Birthweight \\
\hline Overall Sample & $7.0 \pm 4.0$ & $269,253(12.0)$ & $182,960(8.1)$ \\
\hline Racelethnicity (categorical) & $* * *$ & $* * *$ & $* * *$ \\
\hline American Indian / Alaska Native (non-Hispanic) $(n=22,541)$ & $7.0 \pm 4.1$ & $2985(13.3)$ & $1645(7.3)$ \\
\hline Asian American / Pacific Islander (non-Hispanic) $(n=136,921)$ & $4.6 \pm 3.7$ & $14,141(10.4)$ & $11,260(8.2)$ \\
\hline Black (non-Hispanic) $(n=332,437)$ & $7.4 \pm 3.3$ & $57,138(17.2)$ & $44,998(13.5)$ \\
\hline Hispanic/Latinx $(n=532,442)$ & $5.3 \pm 3.7$ & $62,330(11.8)$ & $37,210(7.0)$ \\
\hline White (non-Hispanic) $(n=1,225,658)$ & $7.1 \pm 3.7$ & $132,659(10.8)$ & $87,847(7.2)$ \\
\hline Race/ethnicity (dichotomous) & $* * *$ & $* * *$ & $* * *$ \\
\hline Black (non-Hispanic) $(n=332,437)$ & $7.4 \pm 3.3$ & $57,138(17.2)$ & $44,998(13.5)$ \\
\hline \multicolumn{4}{|l|}{ Non-Black $(n=1,917,563)$} \\
\hline Education & $* * *$ & $* * *$ & $* * *$ \\
\hline Less than high school graduate $(n=404,170)$ & $6.3 \pm 3.7$ & $55,627(13.8)$ & $36,719(9.1)$ \\
\hline High school graduate $(n=569,822)$ & $6.7 \pm 3.7$ & $73,065(12.9)$ & $50,343(8.8)$ \\
\hline Some college $(n=568,116)$ & $6.8 \pm 3.8$ & $67,046(11.8)$ & $45,138(8.0)$ \\
\hline College graduate $(n=602,021)$ & $6.5 \pm 3.7$ & $60,162(10.0)$ & $41,195(6.9)$ \\
\hline
\end{tabular}

Note: Results for categorical variables are unweighted numbers and proportions for each group. Results for continuous variables are means and standard deviations of each measure. $p$-values obtained from $X^{2}$ analyses for categorical variables and one-way ANOVAs for continuous variables. $p$-values significant at *** $p<.001$ 
Table 2 Linear Probability Models Examining Moderating Effects of Race/Ethnicity and Education Level on Relationship between Restrictiveness Index and Adverse Birth Outcomes: Period Linked Live Birth-Infant Death Files, 2005-2015 (N=2,250,000)

\begin{tabular}{|c|c|c|c|}
\hline & & [1] & [2] \\
\hline & & $\begin{array}{l}\text { Preterm Birth } \\
(n=2,058,512)\end{array}$ & $\begin{array}{l}\text { Low Birthweight } \\
(n=2,061,512)\end{array}$ \\
\hline \multirow{7}{*}{$\begin{array}{l}\text { Section A: } \\
\text { Race/ethnicity (categorical) x Restrictiveness Index (RI) }\end{array}$} & Interaction Term & & \\
\hline & RI*AIAN (Non-Hispanic) & $-0.00243[-0.00920,0.00433]$ & $\begin{array}{l}0.0000550[-0.00460 \\
0.00471]\end{array}$ \\
\hline & RI*AAPI (Non-Hispanic) & $\begin{array}{l}-0.00173[-0.00399 \\
0.000526]\end{array}$ & $0.000101[-0.00137,0.00157]$ \\
\hline & Rl*Black (Non-Hispanic) & $0.00247^{*}[0.000145,0.00480]$ & $0.00225[-0.000804,0.00531]$ \\
\hline & RI*Hispanic/Latinx & $-0.00140[-0.00406,0.00126]$ & $\begin{array}{l}-0.00171[-0.00371 \\
0.000281]\end{array}$ \\
\hline & RI*White (Non-Hispanic) & Ref. & Ref. \\
\hline & $\begin{array}{l}\text { Wald Test of Interaction } \\
\text { Term }\end{array}$ & $\begin{array}{l}X^{2}=1.69 \\
p=0.1681\end{array}$ & $\begin{array}{l}X^{2}=2.01 \\
p=0.1068\end{array}$ \\
\hline \multirow{4}{*}{$\begin{array}{l}\text { Section B: } \\
\text { Race/ethnicity (dichotomous) x Restrictiveness Index } \\
\text { (RI) }\end{array}$} & Interaction Term & & \\
\hline & Rl*Black (Non-Hispanic) & $0.00334^{*}[0.000809,0.00587]$ & $0.00292[-0.000134,0.00597]$ \\
\hline & Rl*Non-Black & Ref. & Ref. \\
\hline & $\begin{array}{l}\text { Wald Test of Interaction } \\
\text { Term }\end{array}$ & $\begin{array}{l}X^{2}=7.02 \\
p=0.0107\end{array}$ & $\begin{array}{l}X^{2}=3.69 \\
p=0.0606\end{array}$ \\
\hline \multirow{6}{*}{$\begin{array}{l}\text { Section C: } \\
\text { Education x Restrictiveness Index (RI) }\end{array}$} & Interaction Term & & \\
\hline & RI*Less than $\mathrm{HS}$ & $0.00190[-0.000200,0.00399]$ & $0.00417^{* * *}[0.00178,0.00656]$ \\
\hline & RI*HS grad & $0.00241^{*}[0.000446,0.00436]$ & $0.00360^{* * *}[0.00164,0.00557]$ \\
\hline & Rl*Some college & $0.00186^{*}[0.000327,0.00340]$ & $0.00153^{* *}[0.000407,0.00266]$ \\
\hline & $\mathrm{R}{ }^{*}$ College grad & Ref. & Ref. \\
\hline & $\begin{array}{l}\text { Wald Test of Interaction } \\
\text { Term }\end{array}$ & $\begin{array}{l}X^{2}=2.42 \\
p=0.0766\end{array}$ & $\begin{array}{l}X^{2}=5.17 \\
p=0.0034\end{array}$ \\
\hline
\end{tabular}

Note: Results are marginal effects and $95 \%$ confidence intervals (Cls) from multivariate linear probability models estimating moderating effects of race/ethnicity and education level on the relationship between the standardized lagged restrictiveness index and the probability of preterm birth and low birthweight among all 50 states and Washington, D.C. Final sample size included people not missing any data on moderators, restrictiveness index, outcomes, and covariates. All models adjust for individual-level sociodemographic characteristics, state-level sociodemographic, economic, and political characteristics, and state and year fixed effects. Standard errors clustered at the state level. Wald test of interaction term tests if the interaction term as a whole is statistically significant. $p$-values significant at ${ }^{*} p<.05,{ }^{* *} p<.01,{ }^{* * *} p<.001$

\section{Moderation by race/ethnicity}

When employing the categorical race/ethnicity variable, we found that the relationship between the restrictiveness index and adverse birth outcomes did not vary by an individual's racial/ethnic identity. ${ }^{2}$ However, when employing the dichotomous race/ethnicity variable (Black vs. non-Black), we observed a statistically significant interaction effect on PTB $\left(\chi^{2}=7.02, p<0.05\right)$, indicating that the relationship between a state's restrictiveness index and the probability of PTB differed for Black and non-Black birthing people. A four-policy (one SD) increase in a state's restrictiveness index among Black individuals increased the probability of PTB by 0.33 percentage points (95\% CI: 0.008, 0.59; $p<$ $0.05)$ compared to non-Black individuals, translating to a

\footnotetext{
${ }^{2}$ Although the regression coefficient for RI"Black (non-Hispanic) was statistically significant at $p<0.05$, the interaction term as a whole was not significant.
}

$2.8 \%$ increase in the probability of PTB among the sample (12.0 percentage points).

These effects are presented as predictive margins in Table 3 and the left panel of Fig. 1, where we see the inequity in predicted values of PTB for Black and nonBlack individuals, which worsen as states enact more restrictive abortion policies. In the least restrictive states (-1 SD), the predicted PTB values were $14.5 \%$ for Black birthing people and $11.1 \%$ for non-Black birthing people, a difference of 3.4 percentage points. In the most restrictive states $(+2 \mathrm{SD})$, the predicted value of PTB grew to $15.1 \%$ for Black birthing people and declined to $11 \%$ for non-Black birthing people, a difference of 4.1 percentage points. The right panel of Fig. 1 presents the average marginal effects of being Black (versus nonBlack) on the relationship between the restrictiveness index and the predicted probability of the PTB. As with the predictive margins, we see how the effect of being Black (versus being non-Black) on the predicted 
Table 3 Predictive Margins of Preterm Birth and Low Birthweight from Linear Probability Models Examining Moderating Effects of Race/Ethnicity or Education Level on Relationship between Restrictiveness Index and Adverse Birth Outcomes

\begin{tabular}{|c|c|c|c|c|c|c|c|c|}
\hline & Pretern & & & & Low $\mathrm{Bi}$ & & & \\
\hline & $-1 S D$ & $O S D$ & $+1 S D$ & $+2 S D$ & $-1 S D$ & $O S D$ & $+1 S D$ & $+2 S D$ \\
\hline Race/ethnicity (categ & $x$ Restric & s Index & & & & & & \\
\hline AIAN & 11.6 & 11.2 & 10.9 & 10.6 & 6.3 & 6.0 & 5.8 & 5.6 \\
\hline AAPI & 11.9 & 11.7 & 11.4 & 11.2 & 9.5 & 9.2 & 9.0 & 8.8 \\
\hline Black & 14.5 & 14.7 & 14.8 & 15.0 & 11.4 & 11.4 & 11.4 & 11.5 \\
\hline Hispanic or Latinx & 11.7 & 11.4 & 11.2 & 11.0 & 7.2 & 6.8 & 6.4 & 6.0 \\
\hline White & 11.2 & 11.1 & 11.1 & 11.0 & 7.5 & 7.3 & 7.1 & 6.9 \\
\hline Race/ethnicity (dicho & 5) $x$ Restr & ess Ind & & & & & & \\
\hline Black & 14.5 & 14.7 & 14.9 & 15.1 & 11.5 & 11.5 & 11.5 & 11.5 \\
\hline Non-Black & 11.4 & 11.3 & 11.1 & 11.0 & 7.6 & 7.3 & 7.0 & 6.8 \\
\hline Education Level $x R e$ & eness Ind & & & & & & & \\
\hline LT HS grad & 12.6 & 12.5 & 12.5 & 12.4 & 8.7 & 8.7 & 8.7 & 8.7 \\
\hline HS grad & 12.3 & 12.3 & 12.3 & 12.3 & 8.5 & 8.5 & 8.4 & 8.3 \\
\hline Some college & 12.0 & 11.9 & 11.9 & 11.8 & 8.2 & 7.9 & 7.6 & 7.3 \\
\hline College grad & 10.9 & 10.7 & 10.4 & 10.2 & 7.4 & 6.9 & 6.5 & 6.1 \\
\hline
\end{tabular}

Note: Results are predictive margins of preterm birth and low birthweight for all racial/ethnic and education level subgroups at -1 standard deviation (SD), 0 SD, $+1 \mathrm{SD}$, and $+2 \mathrm{SD}$ of the lagged restrictiveness index. Predictive margin estimates were produced from multivariate linear probability models estimating moderating effects of race/ethnicity or education level on the relationship between the standardized lagged restrictiveness index and the probability of preterm birth and low birthweight among all 50 states and Washington, D.C. Final sample size included people not missing any data on race/ethnicity, education level, restrictiveness index, outcomes, and covariates. All models adjust for individual-level sociodemographic characteristics, state-level sociodemographic, economic, and political characteristics, and state and year fixed effects. Standard errors clustered at the state level

probability of PTB increased as states grew increasingly restrictive.

\section{Moderation by education level}

When examining moderation by education level, we observe a statistically significant interaction effect on LBW $\left(x^{2}=5.17, p<0.01\right)$, indicating that the relationship between a state's restrictiveness index and the probability of LBW differed by an individual's level of education. A four-policy (one SD) increase in a state's restrictiveness index among those with less than a high school education increased the probability of LBW by 0.42 percentage points (95\% CI: $0.18,0.66 ; p<0.001)$ compared to college graduates, a $5.1 \%$ increase in the probability of LBW among the sample (8.3 percentage points). A fourpolicy increase in a state's restrictiveness index among high school graduates increased the probability of LBW by 0.36 percentage points ( $95 \%$ CI: $0.16,0.56 ; p<0.001$ ) compared to college graduates, a $4.3 \%$ increase in the probability of LBW among the sample. Lastly, a fourpolicy increase in a state's restrictiveness index among those attending some college increased the probability of LBW by 0.15 percentage points (95\% CI: $0.04,0.27$; $p<$ 0.01 ) compared to college graduates, a $1.8 \%$ increase in the probability of LBW among the sample.

These effects are presented as predictive margins in Table 3 and the left panel of Fig. 2, where we see the predicted values of LBW for each education level, which decline with additional years of education. In the least restrictive states $(-1 \mathrm{SD})$, the predicted $\mathrm{LBW}$ values were $8.7 \%$ for those with less than a high school degree, $8.5 \%$ for high school graduates, $8.2 \%$ for those with some college, and $7.4 \%$ for college graduates. These inequities worsened as states grew increasingly restrictive; while predicted LBW values remained approximately stable for those with less than a high school degree and high school graduates, they declined by nearly one percentage point for those with some college and by 1.3 percentage points for college graduates. Indeed, in the most restrictive states $(+2 \mathrm{SD})$, the predicted LBW values were $8.7 \%$ for those with less than a high school degree, $8.3 \%$ for high school graduates, $7.3 \%$ for those with some college, and $6.1 \%$ for college graduates. The right panel of Fig. 2 presents the average marginal effects of different education levels (versus college graduates) on the relationship between the restrictiveness index and the predicted probability of LBW. As with the predictive margins, we see how the effect of having less than a high school degree, having a high school degree, or having attended some college (versus having graduated college) on the predicted probability of LBW increased as states grew increasingly restrictive. The inequities between college graduates and all other educational levels were inversely proportional to years of education, with the most severe inequity existing between college graduates and those with less than a high school degree. 


\section{Predictive Margins}

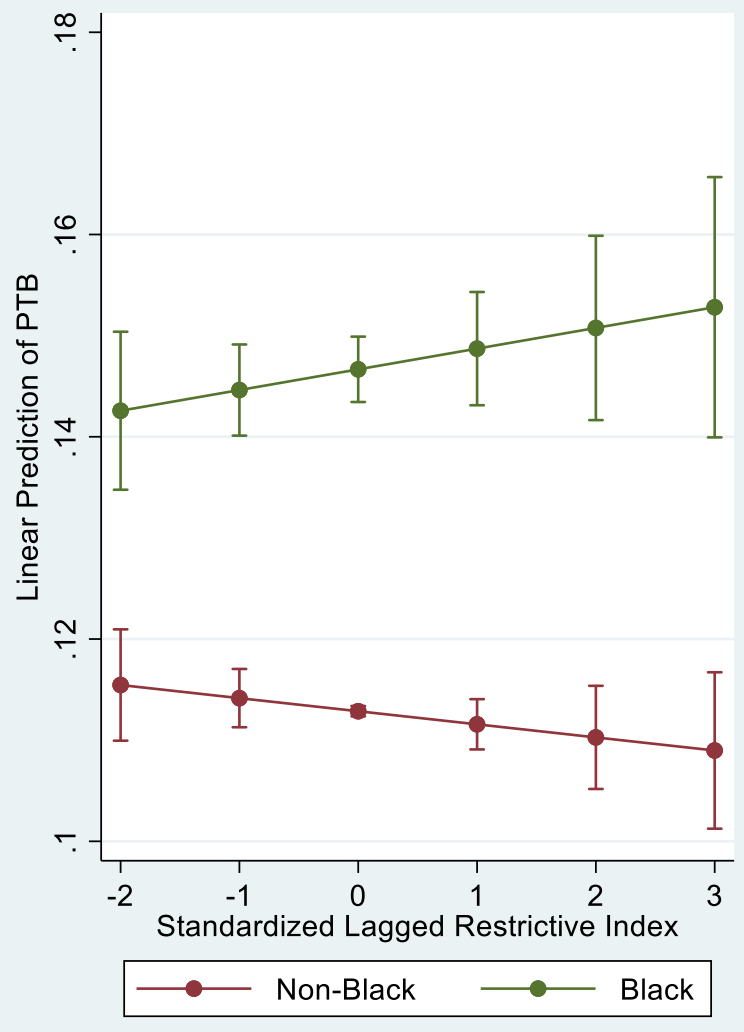

Average Marginal Effects

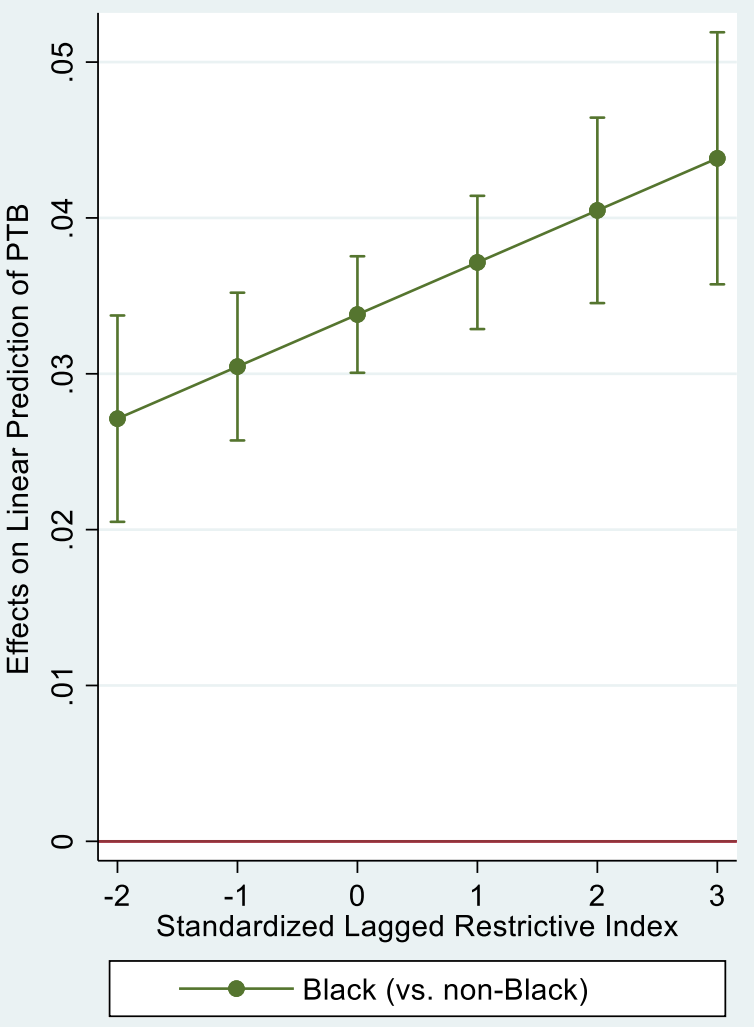

Fig. 1 Predictive Margins and Average Marginal Effects of Racial/Ethnic (Dichotomous) Inequities in Relationship between Restrictiveness Index and Preterm Birth. Note: Results are predictive margins and average marginal effects from multivariate linear probability models estimating the moderating effect of race/ethnicity (dichotomous) on the relationship between the standardized lagged restrictiveness index and the probability of preterm birth among all 50 states and Washington, D.C. Final sample size included people not missing any data on race/ethnicity, restrictiveness index, preterm birth, and covariates. All models adjust for individual-level sociodemographic characteristics, state-level sociodemographic, economic, and political characteristics, and state and year fixed effects. Standard errors clustered at the state level

\section{Moderation by race/ethnicity and education}

Although not presented here, we further investigated the potential for moderation of the relationship between restrictive abortion policies and adverse birth outcomes by race/ethnicity and education via a three-way interaction (see Supplemental Tables 4, 5, 6 and Supplemental Figs. 4, 5, 6, and 7). Briefly, the three-way interaction revealed that increasingly restrictive abortion landscape predicted the likelihood of PTB and LBW to a greater extent for Black birthing people, compared to people of other racial/ethnic identities, across all education levels.

\section{Discussion}

State policymakers have increasingly used policy as a lever to regulate access to abortion services across the United States [2, 6, 42, 60]. Recent evidence highlights the rise of PTB [104, 105] and LBW [106] rates in the United States, specifically among Black and lower SES populations. Restrictive abortion policies may be one mechanism contributing to these adverse birth outcomes. Given the vast racial/ethnic, socioeconomic, and intersecting racial/ethnic and socioeconomic inequities in U.S. birth outcomes [70-86, 88-92, 107, 108] and abortion rates [61-64], along with the knowledge that structural factors directly influence health and health inequities $[35,55-58]$, we sought to examine how the relationship between a state's environment towards abortion access and two key adverse birth outcomes were moderated by race/ethnicity and education level.

Analyses revealed that the relationship between the restrictiveness index and the probability of adverse birth outcomes varied by racial/ethnic identity and education level. For Black individuals, increased exposure to restrictive abortion policies was associated with a $3 \%$ higher probability of PTB compared to non-Black individuals. For those with less than a college degree, 


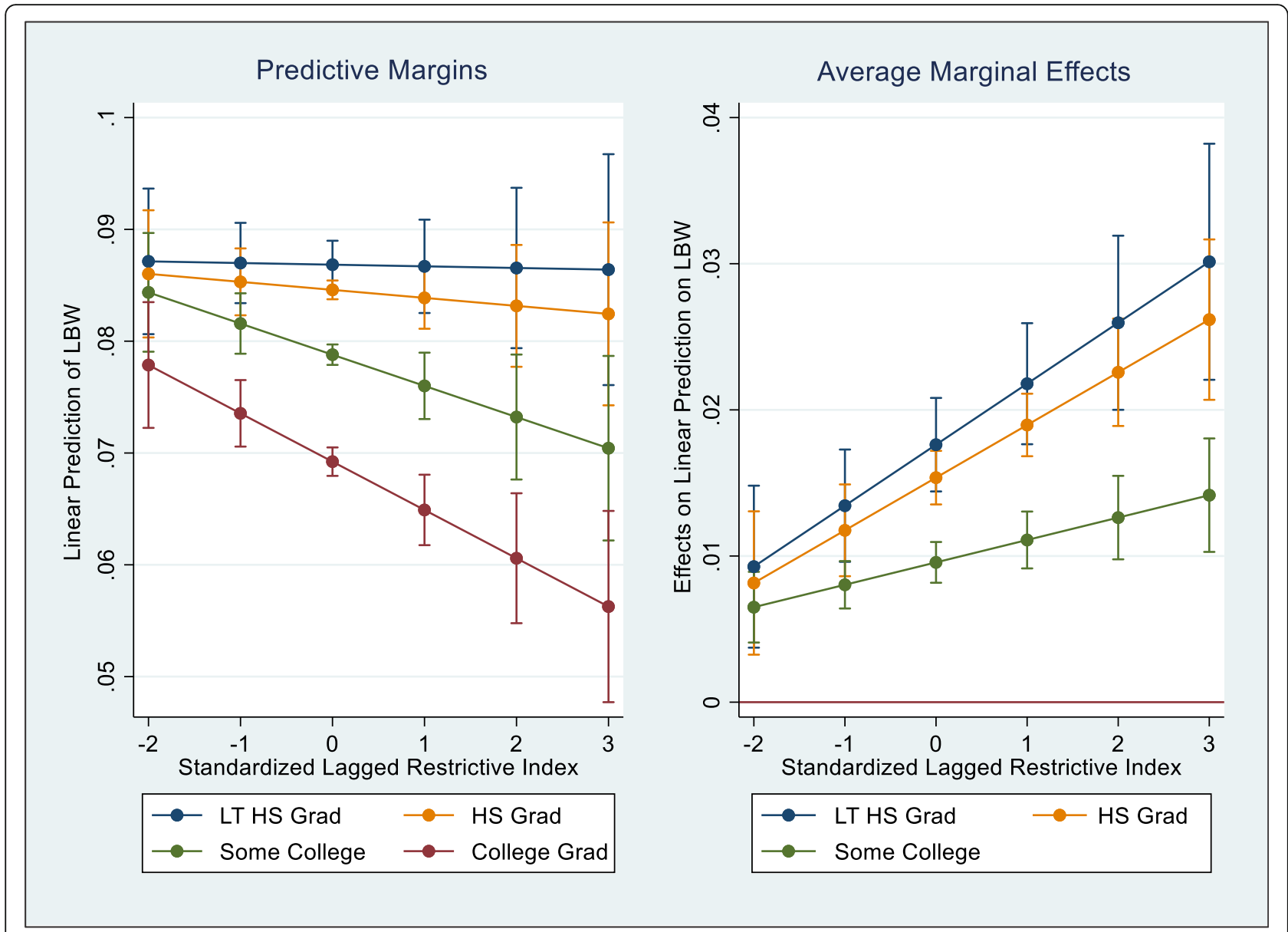

Fig. 2 Predictive Margins and Average Marginal Effects of Educational Inequities in Relationship between Restrictiveness Index and Low Birthweight. Note: Results are predictive margins and average marginal effects from multivariate linear probability models estimating the moderating effect of education level on the relationship between the standardized lagged restrictiveness index and the probability of low birthweight among all 50 states and Washington, D.C. Final sample size included people not missing any data on education level, restrictiveness index, low birthweight, and covariates. All models adjust for individual-level sociodemographic characteristics, state-level sociodemographic, economic, and political characteristics, and state and year fixed effects. Standard errors clustered at the state level

increased exposure to restrictive abortion policies was associated with a 2 to $5 \%$ higher probability of LBW compared to college graduates. In both instances, the inequities between Black and non-Black individuals and those with fewer years of education and college graduates worsened as state environments became increasingly restrictive. With these findings, it is critical to acknowledge in our interpretations that an individual's sociodemographic characteristics - in this case, identifying as Black or having fewer years of education - do not lead to poor health outcomes; the structural and systematic oppression and devaluation of Black and lower SES people lead to poor health outcomes [109].

Although these associations are small in magnitude, these findings have important implications for the health of infants born to Black birthing people and those with fewer years of education, particularly when examining them at the population level. PTB and LBW are two primary factors in infant mortality [110], accounting for $17 \%$ of infant deaths in 2017 [111]. Additionally, infants born preterm or LBW may be more likely to experience negative health and social outcomes as they age [105, 106, 110, 112], including respiratory, gastrointestinal, and cardiovascular disorders [110], decreased language skills and increased language delays [113-117], and diminished educational attainment [118]. Taken together, the weight of these consequences for infants born to Black individuals and those with fewer years of education are immense, particularly given the structural barriers to health, economic security, educational attainment, and access to care that systematically marginalized individuals are disproportionately forced to navigate. Furthermore, our findings suggest that restrictive abortion policies may exacerbate substantial and enduring racial and socioeconomic inequities in infant morbidity in the U.S. 
Although no existing studies have explicitly examined the moderating effects of race/ethnicity and SES on the relationship between restrictive abortion policies and adverse birth outcomes, these findings support existing literature examining how restrictive abortion and reproductive rights policies influence racial and socioeconomic groups differentially. In a pre-post analysis of a restrictive medication abortion policy in Ohio, Upadhyay and colleagues found that, following policy implementation, fewer patients were Black and had lower levels of education [67]. Upon examining fluctuations in Medicaid funding for abortion services in North Carolina, Cook et al. noted that the absence of Medicaid abortion funding was associated with $10 \%$ fewer abortions for Black individuals and 1\% fewer abortions for White individuals [68]. A national analysis by Coles et al. revealed that Black teenagers living in states with Medicaid funding restrictions were four times more likely to experience an unintended birth [69]. Lastly, Sudhinaraset and colleagues found that LBW risk was $8 \%$ lower among Black women living in states with the least restrictive reproductive rights policies, compared to counterparts living in the most restrictive states [53].

These findings encourage further research on sociodemographic inequities in the effects of restrictive abortion policies and other structural determinants of health. For instance, a substantial literature base examines the implications of restrictive abortion policies, yet the vast majority of these studies have not examined sociodemographic inequities in their analyses via estimating moderation effects [119]. The implications of these inequities should also be explored qualitatively, centering the experiences of Black and lower SES individuals and communities who experience adverse birth outcomes due to restrictive abortion policies and other structural determinants of health. Additionally, this work highlights the opportunity to study state policies seeking to improve maternal and infant health and health equity, an area that has received relatively less attention in recent years (compared to research on restrictive policy environments).

\section{Policy implications}

As structural determinants of health, restrictive abortion policies are "upstream determinants ... that shape who has access to health-promoting resources and opportunities" [35]. Our findings - that restrictive abortion policies disproportionately and negatively affect the health of Black individuals and individuals with fewer years of education - highlight the inherent devaluation of Black and lower educated bodies centered at the root of restrictive abortion policies $[33,120]$. In order to combat the perpetuation of these white supremacist values, policymakers at the local, state, and federal levels must prioritize enacting structural interventions to center and protect the health of Black birthing people and those with fewer years of education. Such legislation should focus on dismantling, rebuilding, or redesigning structural systems in order to redistribute resources and opportunities more equitably. At the state level, legislative priorities could include efforts to expand postpartum Medicaid coverage [121, 122], Medicaid coverage of doula services [123], and shifting to communityinformed models of perinatal and reproductive health care $[124,125]$. At the federal level, an excellent example is the Black Maternal Health Momnibus Act of 2021, an act introduced by Congresswomen Alma Adams and Lauren Underwood, Senator Cory Booker, and members of the Black Maternal Health Caucus to address the maternal health crisis in America. Among its many provisions, the Momnibus Act seeks to "make critical investments in social determinants of health that influence maternal health outcomes, like housing, transportation, and nutrition," "provide funding to communitybased organizations ... working to improve maternal health outcomes and promote equity," and "grow and diversify the perinatal workforce to ensure that every mom in America receives culturally congruent maternity care and support" [126].

\section{Limitations}

Although this methodologically rigorous analysis fills critical conceptual gaps in the abortion policy evidence base, it is not without limitations. First, because the restrictiveness index represents a sum of the number of restrictive abortion policies present in a given state during a given year, this measure does not isolate effects of specific restrictive abortion policies, nor does it allow for identification or exploration of the specific causal pathways through which restrictive abortion policies may influence adverse birth outcomes. Furthermore, the composite restrictiveness index treats all policies included as equivalent and does not reflect varied levels of restrictiveness associated with different restrictive abortion policies. However, as our goal was to assess inequities in the relationship between the restrictiveness of an environment toward abortion access on adverse birth outcomes, we that determined the restrictiveness index represented an adequate methodological solution. Second, because educational attainment does not capture information about the quality of an education [127], the neighborhood one lives in, or the financial resources of one's family, community, and state [128-130], it is not a universally comparable indicator of SES. However, data on income - another commonly used indicator of SES $[65,74,131]$ - were inconsistently available in the NCHS data files. Lastly, although we included a robust set of individual- and time-varying state-level covariates 
in these models, this study may be vulnerable to unmeasured time-varying confounding as a limitation of fixed-effects modeling [132].

\section{Conclusions}

Due to the inequitable nature of the economic, political, social, and healthcare systems in the United States, restrictive abortion policies disproportionately affect more vulnerable groups, potentially causing or worsening health inequities. This study examines the differential associations of restrictive abortion policies on adverse birth outcomes. Our findings suggest that Black individuals and those with fewer years of education disproportionately experience negative birth outcomes as exposure to restrictive abortion policies increased, and that these inequities worsen as states grow increasingly restrictive. These findings suggest that restrictive abortion policies may contribute to increases in PTB [104, 105] and LBW [106] rates across the U.S. while simultaneously compounding racial/ethnic and socioeconomic inequities in infant health. As such, this study has important implications for policymakers, who should prioritize enacting policies addressing structural inequities in health and healthcare in order to combat the devaluation of Black and lower educated bodies in the legislative sphere.

\section{Supplementary Information}

The online version contains supplementary material available at https://doi. org/10.1186/s12913-021-07165-x.

\footnotetext{
Additional file 1: Supplemental Table 1. Linear Probability Models Examining Moderating Effect of Race/Ethnicity (Categorical) on Relationship between Restrictiveness Index and Adverse Birth Outcomes: Linked Birth Infant Death Files, 2005-2015. Supplemental Table 2. Linear Probability Models Examining Moderating Effect of Race/Ethnicity (Dichotomous) on Relationship between Restrictiveness Index and Adverse Birth Outcomes: Linked Birth Infant Death Files, 2005-2015. Supplemental Table 3. Linear Probability Models Examining Moderating Effect of Education Level on Relationship between Restrictiveness Index and Adverse Birth Outcomes: Linked Birth Infant Death Files, 2005-2015. Supplemental Table 4. Linear Probability Models Examining Moderating Effect of Race/Ethnicity (Categorical) and Education Level on Relationship between Restrictiveness Index and Adverse Birth Outcomes: Linked Birth Infant Death Files, 2005-2015. Supplemental Table 5. Linear Probability Models Examining Moderating Effect of Race/Ethnicity (Dichotomous) and Education Level on Relationship between Restrictiveness Index and Adverse Birth Outcomes: Linked Birth Infant Death Files, 2005-2015. Supplemental Table 6. Predictive Margins of Preterm Birth and Low Birthweight from Linear Probability Models Examining Moderating Effects of Race/Ethnicity and Education Level on Relationship between Restrictiveness Index and Adverse Birth Outcomes.
}

Additional file 2: Supplemental Figure 1. Predictive Margins and Average Marginal Effects of Racial/Ethnic (Categorical) Inequities in Relationship between Restrictiveness Index and Adverse Birth Outcomes. Supplemental Figure 2. Predictive Margins and Average Marginal Effects of Racial/Ethnic (Dichotomous) Inequities in Relationship between Restrictiveness Index and Low Birthweight. Supplemental Figure 3. Predictive Margins and Average Marginal Effects of Educational Inequities in Relationship between Restrictiveness Index and Preterm Birth. Supplemental Figure 4. Predictive Margins and Average Marginal
Effects of (Categorical) Racial/Ethnic-Educational Inequities in Relationship between Restrictiveness Index and Preterm Birth. Supplemental Figure 5. Predictive Margins and Average Marginal Effects of (Categorical) Racial/ Ethnic-Educational Inequities in Relationship between Restrictiveness Index and Low Birthweight. Supplemental Figure 6. Predictive Margins and Average Marginal Effects of (Dichotomous) Racial/Ethnic-Educational Inequities in Relationship between Restrictiveness Index and Preterm Birth. Supplemental Figure 7. Predictive Margins and Average Marginal Effects of (Dichotomous) Racial/Ethnic-Educational Inequities in Relationship between Restrictiveness Index and Low Birthweight.

\section{Abbreviations}

AAPI: Asian American / Pacific Islander; AIAN: American Indian / Alaska Native; LBW: Low birthweight; NCHS: National Center for Health Statistics; PTB: Preterm birth; SD: Standard deviation; SES: Socioeconomic status

\section{Acknowledgements}

Not applicable.

\section{Authors' contributions}

SKR, WSR, MSA, BS, MW, and KSH contributed to conceptualization and design of the study. WSR, MSA, BS, and MW acquired the data, and SKR conducted all analyses and provided initial interpretation of the data. WSR, $M S A, S B, B S, M W$, and KSH contributed to interpretation of the data. SKR wrote the draft manuscript and WSR, MSA, SB, ZJ, BS, MW, and KSH provided substantial revisions of draft manuscripts. All authors approve the final manuscript and agree to be accountable for their contributions.

\section{Authors' information}

Not applicable

\section{Funding}

This research was supported by a predoctoral fellowship from the Center for Reproductive Health Research in the Southeast (RISE) and in part with grant support from the Society of Family Planning Research Fund (SFPRF11-18). The views and opinions expressed are those of the authors, and do not necessarily represent the views and opinions of SFPRF. Neither funding body played a role in the design of the study, collection, analysis, and interpretation of data, or in writing the manuscript.

\section{Availability of data and materials}

The data that support the findings of this study are available from the National Center for Health Statistics but restrictions apply to the availability of these micro-data, which were used under license for the current study, and so are not publicly available. Researchers interested in applying for access to restricted-use micro-data files should contact the National Center for Health Statistics

\section{Declarations}

\section{Ethics approval and consent to participate}

The Institutional Review Board of Emory University deemed this project exempt from review as it does not constitute human subjects research.

\section{Consent for publication}

Not applicable.

\section{Competing interests}

The authors declare that they have no competing interests.

\section{Author details}

${ }^{1}$ Department of Health Policy and Management, Rollins School of Public Health, Emory University, 1518 Clifton Rd NE, Atlanta, GA 30322, USA. ${ }^{2}$ Center for Reproductive Health Research in the Southeast (RISE), Emory University, 1518 Clifton Rd NE, Atlanta, GA 30322, USA. 'Department of Behavioral, Social, and Health Education Sciences, Rollins School of Public Health, Emory University, 1518 Clifton Rd NE, Atlanta, GA 30322, USA. ${ }^{4}$ Department of Health Services Administration, School of Health Professions, University of Alabama at Birmingham, 1719 9th Ave. S, Birmingham, AL 35233, USA. ${ }^{5}$ Independent Clinician Scholar, Atlanta, GA 30322, USA. ${ }^{6}$ Department of 
Health Care Organization and Policy, School of Public Health, University of Alabama at Birmingham, 1665 University Blvd, Birmingham, AL 35233, USA. ${ }^{7}$ Department of Population and Family Health, Mailman School of Public Health, Columbia University, 722 West 168th St, New York, NY 10032, USA.

\section{Received: 6 July 2021 Accepted: 12 October 2021}

Published online: 22 October 2021

\section{References}

1. Guttmacher Institute. An overview of abortion Laws. Guttmacher Institute; 2020

2. Guttmacher Institute. State abortion policy landscape: from hostile to supportive. Guttmacher Institute; 2020.

3. Bentele KG, Sager R, Aykanian A. Rewinding roe v. Wade: understanding the accelerated adoption of state-level restrictive abortion legislation, 20082014. J Women Politics Policy. 2018;39(4):490-517. https://doi.org/10.1080/1 554477X.2018.1511123.

4. Guttmacher Institute. State Policies on Abortion. [Available from: https:// www.guttmacher.org/united-states/abortion/state-policies-abortion. Accessed 1 Aug 2020

5. Upadhyay UD, McCook AA, Bennett AH, Cartwright AF, Roberts SCM. State abortion policies and Medicaid coverage of abortion are associated with pregnancy outcomes among individuals seeking abortion recruited using Google ads: a national cohort study. Soc Sci Med. 2021;274:113747. https:// doi.org/10.1016/j.socscimed.2021.113747.

6. Blank RM, George CC, London RA. State abortion rates: the impact of policies, providers, politics, demographics, and economic environment. J Health Econ. 1996;15(5):513-53. https://doi.org/10.1016/S0167-6296(96)004 94-8.

7. Brown BP, Hebert LE, Gilliam M, Kaestner R. Association of highly restrictive state abortion policies with abortion rates, 2000-2014. JAMA Netw Open. 2020;3(11):e2024610. https://doi.org/10.1001/jama networkopen.2020.24610.

8. Fischer $\mathrm{S}$, Royer $\mathrm{H}$, White $\mathrm{C}$. The impact of reduced access to abortion and family planning services on abortions, births, and contraceptive purchases. J Public Econ. 2018;167:43-68. https://doi.org/10.1016/j.jpubeco.2018.08.009.

9. Grossman D, Baum S, Fuentes L, White K, Hopkins K, Stevenson A, et al. Change in abortion services after implementation of a restrictive law in Texas. Contraception. 2014;90(5):496-501. https://doi.org/10.1016/j.contra ception.2014.07.006.

10. Haas-Wilson D. The economic impact of state restrictions on abortion: parental consent and notification laws and Medicaid funding restrictions. Policy Anal Manage. 1993;12(3):498-511. https://doi.org/10.2307/3325303.

11. Levine PB, Trainor AB, Zimmerman DJ. The effect of Medicaid abortion funding restrictions on abortions, pregnancies and births. J Health Econ. 1996;15(5):555-78. https://doi.org/10.1016/S0167-6296(96)00495-X.

12. Lindo JM, Myers C, Schlosser A, Cunningham S. How far is too far? New evidence on abortion clinic closures, access, and abortions. National Bureau of Economic Research; 2017.

13. Matthews S, Ribar D, Wilhelm M. The effects of economic conditions and access to reproductive health services on state abortion rates and birthrates. Fam Plan Perspect. 1997;29(2):52-60. https://doi.org/10.2307/2953362.

14. New MJ. Analyzing the effect of anti-abortion U.S. state legislation in the post-Casey era. State Polit Policy Quart. 2011;11(1):28-47. https://doi.org/1 $0.1177 / 1532440010387397$.

15. Oakley MR. Abortion restrictions and abortion rates: has state abortion policy been successful? Polit Policy. 2003;31(3):472-87. https://doi.org/1 0.1111/j.1747-1346.2003.tb00158.x.

16. Ohsfeldt RL, Gohmann SF. Do parental involvement laws reduce adolescent abortion rates? Contemp Econ Policy. 1994;12(2):65-76. https://doi.org/1 0.1111/j.1465-7287.1994.tb00424.x

17. Zane S, Creanga AA, Berg CJ, Pazol K, Suchdev DB, Jamieson DJ, et al. Abortion-related mortality in the United States: 1998-2010. Obstet Gynecol. 2015;126(2):258-65. https://doi.org/10.1097/AOG.0000000000000945.

18. Bitler M, Zavodny M. The effect of abortion restrictions on the timing of abortions. J Health Econ. 2001;20(6):1011-32. https://doi.org/10.1016/S01676296(01)00106-0.

19. Althaus FA, Henshaw SK. The effects of mandatory delay laws on abortion patients and providers. Fam Plan Perspect. 1994;26(5):228-33. https://doi. org/10.2307/2135944.
20. Joyce T, Henshaw SK, Skatrud JD. The impact of Mississippi's mandatory delay law on abortions and births. JAMA. 1997;278(8):653-8. https://doi. org/10.1001/jama.1997.03550080063040.

21. Joyce T, Kaestner R. The impact of Mississippi's mandatory delay law on the timing of abortion. Fam Plan Perspect. 2000;32(1):4-13. https://doi.org/10.23 07/2648143.

22. Currie J, Nixon L, Cole N. Restrictions on Medicaid funding of abortion: effects on birth weight and pregnancy resolutions. J Hum Resour. 1996: 31(1):159-88. https://doi.org/10.2307/146046.

23. Lichter DT, McLaughlin DK, Ribar DC. State abortion policy, geographic access to abortion providers and changing family formation. Fam Plan Perspect. 1998;30(6):281-7. https://doi.org/10.2307/2991504.

24. Williams SG, Roberts S, Kerns JL. Effects of legislation regulating abortion in Arizona. Womens Health Issues. 2018;28(4):297-300. https://doi.org/10.1016/ j.whi.2018.02.002.

25. Texas Policy Evaluation Project. Abortion wait times in Texas: the shrinking capacity of facilities and the potential impact of closing non-ASC clinics. 2015

26. Reeves MF, Blumenthal PD, Jones RK, Nichols MD, Saporta VA. New research at the 2015 National Abortion Federation Annual Meeting: putting research into practice. Contraception. 2015;91(5):359. https://doi.org/10.1016/j.contra ception.2015.02.010.

27. Jones RK, Jerman J. How far did US women travel for abortion services in 2008? J Women's Health (Larchmt). 2013;22(8):706-13. https://doi.org/10.1 089/jwh.2013.4283.

28. Jerman J, Frohwirth L, Kavanaugh ML, Blades N. Barriers to abortion care and their consequences for patients traveling for Services: qualitative findings from two states. Perspect Sex Reprod Health. 2017;49(2):95-102. https://doi.org/10.1363/psrh.12024.

29. Roberts SC, Turok DK, Belusa E, Combellick S, Upadhyay UD. Utah's 72-hour waiting period for abortion: experiences among a clinic-based sample of women. Perspect Sex Reprod Health. 2016;48(4):179-87. https://doi.org/1 $0.1363 / 48 \mathrm{e} 8216$

30. Fuentes L, Lebenkoff S, White K, Gerdts C, Hopkins K, Potter JE, et al. Women's experiences seeking abortion care shortly after the closure of clinics due to a restrictive law in Texas. Contraception. 2016;93(4):292-7. https://doi.org/10.1016/j.contraception.2015.12.017.

31. Gerdts C, Fuentes L, Grossman D, White K, Keefe-Oates B, Baum SE, et al. Impact of clinic closures on women obtaining abortion services after implementation of a restrictive law in Texas. Am J Public Health. 2016; 106(5):857-64. https://doi.org/10.2105/AJPH.2016.303134

32. Baum SE, White K, Hopkins K, Potter JE, Grossman D. Women's experience obtaining abortion care in Texas after implementation of restrictive abortion Laws: a qualitative study. PLoS One. 2016;11(10):e0165048. https://doi.org/1 0.1371/journal.pone.0165048

33. Ross $\amalg$, Solinger R. Reproductive justice: an introduction. Oakland: University of California Press; 2017. https://doi.org/10.1525/9780520963207.

34. Roberts D. Killing the black body: race, reproduction, and the meaning of liberty. 2nd ed. New York: Vintage Books; 2017.

35. Crear-Perry J, Correa-de-Araujo R, Lewis Johnson T, McLemore MR, Neilson E, Wallace M. Social and structural determinants of health inequities in maternal health. J Women's Health (Larchmt). 2020;30(2):230-5. https://doi. org/10.1089/jwh.2020.8882.

36. Geller SE, Koch AR, Garland CE, MacDonald EJ, Storey F, Lawton B. A global view of severe maternal morbidity: moving beyond maternal mortality. Reprod Health. 2018;15(Suppl 1):98. https://doi.org/10.1186/s12978-018-052 7-2.

37. Grimes DA. Estimation of pregnancy-related mortality risk by pregnancy outcome, United States, 1991 to 1999. Am J Obstet Gynecol. 2006;194(1): 92-4. https://doi.org/10.1016/j.ajog.2005.06.070.

38. Raymond EG, Grimes DA. The comparative safety of legal induced abortion and childbirth in the United States. Obstet Gynecol. 2012;119(2 Pt 1):215-9. https://doi.org/10.1097/AOG.0b013e31823fe923.

39. Biggs MA, Upadhyay UD, McCulloch CE, Foster DG. Women's mental health and well-being 5 years after receiving or being denied an abortion: a prospective, longitudinal cohort study. JAMA Psychiatry. 2017;74(2):169-78. https://doi.org/10.1001/jamapsychiatry.2016.3478.

40. Gerdts C, Dobkin L, Foster DG, Schwarz EB. Side effects, physical health consequences, and mortality associated with abortion and birth after an unwanted pregnancy. Womens Health Issues. 2016;26(1):55-9. https://doi. org/10.1016/j.whi.2015.10.001. 
41. Ibis Reproductive Health and Center for Reproductive Rights. Evaluating Abortion Restrictions and Supportive Policy Across the United States 2020 Available from: https://evaluatingpriorities.org/.

42. Krieger N, Gruskin S, Singh N, Kiang MV, Chen JT, Waterman PD, et al. Reproductive justice and the pace of change: socioeconomic trends in US infant death rates by legal status of abortion, 1960-1980. Am J Public Health. 2015;105(4):680-2. https://doi.org/10.2105/AJPH.2014.302401.

43. Wallace ME, Evans MG, Theall $K$. The status of women's reproductive rights and adverse birth outcomes. Womens Health Issues. 2017;27(2):121-8. https://doi.org/10.1016/j.whi.2016.12.013.

44. Hobel CJ, Goldstein A, Barrett ES. Psychosocial stress and pregnancy outcome. Clin Obstet Gynecol. 2008;51(2):333-48. https://doi.org/10.1097/ GRF.0b013e31816f2709.

45. Lobel M, DeVincent CJ, Kaminer A, Meyer BA. The impact of prenatal maternal stress and optimistic disposition on birth outcomes in medically high-risk women. Health Psychol. 2000;19(6):544-53. https://doi.org/10.1037/ 0278-6133.19.6.544.

46. Osborne LM, Monk C. Perinatal depression--the fourth inflammatory morbidity of pregnancy?: theory and literature review. Psychoneuroendocrinology. 2013;38(10):1929-52. https://doi.org/10.1016/j. psyneuen.2013.03.019.

47. Pabayo R, Ehntholt A, Cook DM, Reynolds M, Muennig P, Liu SY. Laws restricting access to abortion services and infant mortality risk in the United States. Int J Environ Res Public Health. 2020;17(11):3773.

48. Sen B. State abortion restrictions and child fatal-injury: an exploratory study. South Econ J. 2007;73(3):553-74. https://doi.org/10.1002/j.2325-8012.2007. tb00789.x.

49. Sen B, Wingate MS, Kirby R. The relationship between state abortionrestrictions and homicide deaths among children under 5 years of age: a longitudinal study. Soc Sci Med. 2012;75(1):156-64. https://doi.org/10.1016/j. socscimed.2012.01.037

50. Bitler M, Zavodny M. Child abuse and abortion availability. Am Econ Rev. 2002;92(2):363-7. https://doi.org/10.1257/000282802320191624.

51. Hawkins SS, Ghiani M, Harper S, Baum CF, Kaufman JS. Impact of state-level changes on maternal mortality: a population-based, quasi-experimental study. Am J Prev Med. 2020;58(2):165-74. https://doi.org/10.1016/j.amepre.2 019.09.012.

52. Karletsos D, Stoecker C, Vilda D, Theall KP, Wallace ME. Association of State gestational age limit abortion laws with infant mortality. Am J Prev Med. 2021.https://www.ajpmonline.org/article/S0749-3797(21)00353-6/fulltext.

53. Sudhinaraset M, Vilda D, Gipson JD, Bornstein M, Wallace ME. Women's reproductive rights policies and adverse birth outcomes: a state-level analysis to assess the role of race and nativity status. Am J Prev Med. 2020; 59(6):787-95. https://doi.org/10.1016/j.amepre.2020.07.025.

54. Vilda D, Wallace ME, Daniel C, Evans MG, Stoecker C, Theall KP. State abortion policies and maternal death in the United States, 2015-2018. Am J Public Health. 2021:111(9):1696-704.

55. Solar O, Irwin A. A conceptual framework for action on the social determinants of Health: social determinants of Health discussion paper 2. World Health Organization; 2010.

56. Bailey ZD, Krieger N, Agenor M, Graves J, Linos N, Bassett MT. Structural racism and health inequities in the USA: evidence and interventions. Lancet. 2017;389(10077):1453-63. https://doi.org/10.1016/S0140-6736(17)30569-X.

57. McLeroy KR, Bibeau D, Steckler A, Glanz K. An ecological perspective on health promotion programs. Health Educ Q. 1988;15(4):351-77. https://doi. org/10.1177/109019818801500401.

58. Krieger $\mathrm{N}$. Theories for social epidemiology in the 21 st century: an ecosocial perspective. Int J Epidemiol. 2001;30(4):668-77. https://doi.org/10.1093/ije/3 0.4.668.

59. Kelly M. Regulating the reproduction and mothering of poor women: the controlling image of the welfare mother in television news coverage of welfare reform. J Poverty. 2010;14(1):76-96. https://doi.org/10.1080/10875540903489447.

60. American Public Health Association. Restricted access to abortion violates human rights, precludes reproductive justice, and demands public Health intervention. 2015

61. Dehlendorf C, Harris LH, Weitz TA. Disparities in abortion rates: a public health approach. Am J Public Health. 2013;103(10):1772-9. https://doi.org/1 0.2105/AJPH.2013.301339.

62. Dehlendorf C, Weitz T. Access to abortion services: a neglected health disparity. J Health Care Poor Underserved. 2011;22(2):415-21. https://doi. org/10.1353/hpu.2011.0064.
63. Jones RK, Kavanaugh ML. Changes in abortion rates between 2000 and 2008 and lifetime incidence of abortion. Obstet Gynecol. 2011;117(6):135866. https://doi.org/10.1097/AOG.0b013e31821c405e.

64. Jones RK, Kost K, Singh S, Henshaw SK, Finer LB. Trends in abortion in the United States. Clin Obstet Gynecol. 2009;52(2):119-29. https://doi.org/10.1 097/GRF.0b013e3181a2af8f.

65. Williams DR, Purdie-Vaughns V. Needed interventions to reduce racial/ ethnic disparities in Health. J Health Polit Policy Law. 2016;41(4):627-51. https://doi.org/10.1215/03616878-3620857.

66. Williams DR, Mohammed SA. Discrimination and racial disparities in health: evidence and needed research. J Behav Med. 2009;32(1):20-47. https://doi. org/10.1007/s10865-008-9185-0.

67. Upadhyay UD, Johns NE, Cartwright AF, Franklin TE. Sociodemographic characteristics of women able to obtain medication abortion before and after Ohio's law requiring use of the Food and Drug Administration protocol. Health Equity. 2018;2(1):122-30. https://doi.org/10.1089/heq.2018. 0002.

68. Cook PJ, Parnell AM, Moore MJ, Pagnini D. The effects of short-term variation in abortion funding on pregnancy outcomes. J Health Econ. 1999; 18(2):241-57. https://doi.org/10.1016/S0167-6296(98)00048-4.

69. Coles MS, Makino KK, Stanwood NL, Dozier A, Klein JD. How are restrictive abortion statutes associated with unintended teen birth? J Adolesc Health 2010;47(2):160-7. https://doi.org/10.1016/j.jadohealth.2010.01.003.

70. Committee on Understanding Premature Birth and Assuring Healthy Outcomes. Preterm birth: causes, consequences, and prevention. Washington, DC: Institute of Medicine; 2007.

71. Ventura SJ, Martin JA, Curtin SC, Mathews TJ. Report of final natality statistics, 1996. Mon Vital Stat Rep. 1998;46(11 Suppl):1-99.

72. Kramer MS, Seguin L, Lydon J, Goulet L. Socio-economic disparities in pregnancy outcome: why do the poor fare so poorly? Paediatr Perinat Epidemiol. 2000;14(3): 194-210. https://doi.org/10.1046/j.1365-3016.2000.00266.x.

73. Collins JW Jr, Wambach J, David RJ, Rankin KM. Women's lifelong exposure to neighborhood poverty and low birth weight: a population-based study. Matern Child Health J. 2009;13(3):326-33. https://doi.org/10.1007/s10995008-0354-0.

74. Blumenshine P, Egerter S, Barclay CJ, Cubbin C, Braveman PA Socioeconomic disparities in adverse birth outcomes: a systematic review. Am J Prev Med. 2010;39(3):263-72. https://doi.org/10.1016/j.amepre.2010.05. 012.

75. Lhila A, Long S. What is driving the black-white difference in low birthweight in the US? Health Econ. 2012;21(3):301-15. https://doi.org/10.1 002/hec.1715

76. Mathews TJ, MacDorman MF. Infant mortality statistics from the 2009 period linked birth/infant death data set. Natl Vital Stat Rep. 2013;61(8):1-27.

77. Bushnik T, Yang S, Kaufman JS, Kramer MS, Wilkins R. Socioeconomic disparities in small-for-gestational-age birth and preterm birth. Health Rep. 2017:28(11):3-10.

78. Burris $\mathrm{HH}$, Hacker MR. Birth outcome racial disparities: a result of intersecting social and environmental factors. Semin Perinatol. 2017;41(6):360-6. https:// doi.org/10.1053/j.semperi.2017.07.002

79. Martin JA, Hamilton BE, Osterman MJK, Driscoll AK, Drake P. Births: final data for 2018. Natl Vital Stat Rep. 2019;68(13):1-47.

80. Lu MC, Halfon N. Racial and ethnic disparities in birth outcomes: a lifecourse perspective. Matern Child Health J. 2003;7(1):13-30. https://doi.org/1 0.1023/A:1022537516969.

81. MacDorman MF. Race and ethnic disparities in fetal mortality, preterm birth, and infant mortality in the United States: an overview. Semin Perinatol. 2011;35(4):200-8. https://doi.org/10.1053/j.semperi.2011.02.017.

82. Komro KA, Markowitz S, Livingston MD, Wagenaar AC. Effects of state-level earned income tax credit Laws on birth outcomes by race and ethnicity. Health Equity. 2019;3(1):61-7. https://doi.org/10.1089/heq.2018.0061.

83. Rosenthal L, Lobel M. Explaining racial disparities in adverse birth outcomes: unique sources of stress for black American women. Soc Sci Med. 2011; 72(6):977-83. https://doi.org/10.1016/j.socscimed.2011.01.013.

84. Wallace ME, Mendola P, Kim SS, Epps N, Chen Z, Smarr M, et al. Racial/ ethnic differences in preterm perinatal outcomes. Am J Obstet Gynecol. 2017;216(3):306 e1-e12.

85. Braveman PA, Cubbin C, Egerter S, Williams DR, Pamuk E. Socioeconomic disparities in health in the United States: what the patterns tell us. Am J Public Health. 2010;100(Suppl 1):S186-96. https://doi.org/10.2105/AJPH.2 009.166082 
86. Braveman PA, Heck K, Egerter S, Marchi KS, Dominguez TP, Cubbin C, et al. The role of socioeconomic factors in black-White disparities in preterm birth. Am J Public Health. 2015;105(4):694-702. https://doi.org/10.2105/A JPH.2014.302008.

87. Crenshaw KW. Mapping the margins: intersectionality, identity politics, and violence against women of color. Stanford Law Rev. 1991;43(6):1241-99. https://doi.org/10.2307/1229039.

88. Johnson JD, Green CA, Vladutiu CJ, Manuck TA. Racial Disparities in Prematurity Persist among Women of High Socioeconomic Status. Am J Obstet Gynecol MFM. 2020;2(3):100104.

89. Hamilton D. Post-racial rhetoric, racial Health disparities, and Health disparity consequences of stigma, stress, and racism. Washington, DC: Washington Center for Equitable Growth; 2017.

90. Kothari CL, Paul R, Dormitorio B, Ospina F, James A, Lenz D, et al. The interplay of race, socioeconomic status and neighborhood residence upon birth outcomes in a high black infant mortality community. SSM Popul Health. 2016:2:859-67. https://doi.org/10.1016/j.ssmph.2016.09.011.

91. Smith IZ, Bentley-Edwards KL, El-Amin S, Darity W. Fighting at birth: eradicating the black-White infant mortality gap. Oakland: Duke University; 2018.

92. Williams DR, Mohammed SA, Leavell J, Collins C. Race, socioeconomic status, and health: complexities, ongoing challenges, and research opportunities. Ann N Y Acad Sci. 2010;1186(1):69-101. https://doi.org/1 0.1111/j.1749-6632.2009.05339.x.

93. Johnson J, Green C, Vladutiu C, Manuck T. 44: racial disparities in prematurity persist among women of high socioeconomic status (SES). Am J Obstet Gynecol. 2020;222(1):S37-S8. https://doi.org/10.1016/j.ajog.2019.11. 060.

94. World Health Organization. International statistical classification of diseases and related Health problems, 10th revision, edition 2010. Geneva: World Health Organization; 2010.

95. National Center for Health Statistics. Period Linked Live Birth-Infant Death Files: 2005-2015. Accessed 1 Sept 2018.

96. NARAL Pro-Choice America. State Governments. [Available from: https:// www.prochoiceamerica.org/laws-policy/state-government/. Accessed 1 Aug 2018.

97. The Policy Surveillance Program. Abortion Law Project 2019 Available from: http://lawatlas.org/page/abortion-law-project.

98. Hatzenbuehler ML, Prins SJ, Flake M, Philbin M, Frazer MS, Hagen D, et al. Immigration policies and mental health morbidity among Latinos: a statelevel analysis. Soc Sci Med. 2017;174:169-78. https://doi.org/10.1016/j. socscimed.2016.11.040.

99. Women's Health and Safety Act, 2013 Al. HB 57, 2013 Alabama state legislature, 2013 regular session Sess. 2013.

100. Bailey ZD, Feldman JM, Bassett MT. How structural racism works - racist policies as a root cause of U.S. racial health inequities. N Engl J Med. 2021; 384(8):768-73. https://doi.org/10.1056/NEJMms2025396.

101. Wooldridge JM. Introductory econometrics: a modern approach. 5th ed. Mason: South-Western; 2013.

102. Woolridge JM. Econometric analysis of cross section and panel data. 3rd ed. Cambridge: MIT Press; 2010.

103. Bertrand M, Duflo E, Mullainathan S. How much should we trust differences-indifferences estimates? Q J Econ. 2004;1 19(1):249-75. https:/doi.org/10.1162/0033 55304772839588

104. Centers for Disease Control and Prevention. Preterm Birth. [Available from: https://www.cdc.gov/reproductivehealth/maternalinfanthealth/pretermbirth. htm. Accessed 1 Mar 2020

105. Martin JA, MJK O. Describing the Increase in Preterm Births in the United States, 2014-2016: Centers of disease control and prevention; 2018. Contract No.: No. 312.

106. Womack LS, Rossen LM, Martin JA. Singleton Low Birthweight Rates, by Race and Hispanic Origin: United States, 2006-2016. Centers of disease control and prevention; 2018. Contract No.: No. 306.

107. Committee on Study the Prevention of Low Birth Weight. Preventing low Birthweight. Washington, DC: Institute of Medicine; 1985.

108. Cramer JC. Racial and ethnic differences in birthweight: the role of income and financial assistance. Demography. 1995;32(2):231-47. https://doi.org/1 $0.2307 / 2061742$

109. Boyd RW, Lindo EG, Weeks LD, McLemore MR. Health Affairs Blog: Health Affairs. 2020. [cited 2021]. Available from: https://www.healthaffairs.org/do/1 0.1377/hblog20200630.939347/full/?utm_medium=social\&amp\%3Butm_
source=twitter\&amp\%3Butm_campaign=blog\&amp\%3Butm_content= Boyd\&amp\%3B=.

110. Institute of Medicine (US). Committee on Understanding Premature Birth and Assuring Healthy Outcomes. In: Behrman RE, Butler AS, editors. Preterm Birth: Causes, Consequences, and Prevention. Washington (DC): The National Academies Collection: Reports funded by National Institutes of Health; 2007.

111. Kochanek KD, Murphy SL, Xu J, Arias E. Deaths: final data for 2017. Natl Vital Stat Rep. 2019;68(9):1-77.

112. Logan C, Holcombe E, Manlove J, Ryan S. The Consequences of Unintended Childbearing: A White Paper; 2007.

113. de Jong M, Verhoeven M, van Baar AL. School outcome, cognitive functioning, and behaviour problems in moderate and late preterm children and adults: a review. Semin Fetal Neonatal Med. 2012;17(3):163-9. https://doi.org/10.1016/j.siny.2012.02.003.

114. Dong Y, Chen SJ, Yu JL. A systematic review and meta-analysis of long-term development of early term infants. Neonatology. 2012;102(3):212-21. https://doi.org/10.1159/000338099.

115. van Noort-van der Spek IL, Franken MC, Weisglas-Kuperus N. Language functions in preterm-born children: a systematic review and meta-analysis Pediatrics. 2012;129(4):745-54. https://doi.org/10.1542/peds.2011-1728.

116. Wolke D, Samara M, Bracewell M, Marlow N, Group EPS. Specific language difficulties and school achievement in children born at 25 weeks of gestation or less. J Pediatr. 2008;152(2):256-62. https://doi.org/10.1016/j. jpeds.2007.06.043.

117. Zambrana IM, Vollrath ME, Jacobsson B, Sengpiel V, Ystrom E. Preterm birth and risk for language delays before school entry: a sibling-control study. Dev Psychopathol. 2020;33(1):1-6. https://doi.org/10.1017/S0954579419001536.

118. Bilgin A, Mendonca M, Wolke D. Preterm birth/low birth weight and markers reflective of wealth in adulthood: a meta-analysis. Pediatrics. 2018; 142(1):e20173625.

119. Livingston MD, Haardorfer R. A gentle introduction to mediation and moderation. J Pediatr. 2019;214:246-8. https://doi.org/10.1016/j.jpeds.2019. 08.066 .

120. Roberts SCM, Fuentes L, Berglas NF, Dennis AJ. A 21st-century public health approach to abortion. Am J Public Health. 2017;107(12):1878-82. https://doi. org/10.2105/AJPH.2017.304068.

121. National Academy for State Health Policy. View Each State's Efforts to Extend Medicaid Coverage to Postpartum Women 2021 Available from: https://www.nashp.org/view-each-states-efforts-to-extend-medicaid-covera ge-to-postpartum-women/.

122. Taylor JK, Asiodu IV, Mehra R, Alspaugh A, Bond T, Franck LS, et al. We Must Extend Postpartum Medicaid Coverage. Sci Am. 2021; Available from: https://www.scientificamerican.com/article/we-must-extend-postpartummedicaid-coverage/.

123. Ancient Song Doula Services. Village birth international, every mother counts. In: Bey A, Brill A, Porchia-Albert C, et al., editors. Advancing Birth Justice: Community-Based Doula Models as a Standard of Care for Ending Racial Disparities; 2019.

124. Julian Z, Robles D, Whetstone S, Perritt JB, Jackson AV, Hardeman RR, et al. Community-informed models of perinatal and reproductive health services provision: a justice-centered paradigm toward equity among black birthing communities. Semin Perinatol. 2020;44(5):151267. https://doi.org/10.1016/j. semperi.2020.151267.

125. Hardeman RR, Karbeah J, Kozhimannil KB. Applying a critical race lens to relationship-centered care in pregnancy and childbirth: an antidote to structural racism. Birth. 2020;47(1):3-7. https://doi.org/10.1111/birt.12462.

126. Black Maternal Health Caucus. Black Maternal Health Momnibus Act of 2021 2021 Available from: https://blackmaternalhealthcaucus-underwood.house. gov/Momnibus.

127. Galobardes B, Shaw M, Lawlor DA, Lynch JW, Davey SG. Indicators of socioeconomic position (part 1). J Epidemiol Community Health. 2006;60(1): 7-12. https://doi.org/10.1136/jech.2004.023531.

128. Zajacova A, Lawrence EM. The relationship between education and Health: reducing disparities through a contextual approach. Annu Rev Public Health. 2018;39(1):273-89. https://doi.org/10.1146/annurev-publhealth-03181 6-044628.

129. Eng N. Education inequality: broadening public attitudes through framing. J Soc Issues. 2016;72(4):676-95. https://doi.org/10.1111/josi.12189.

130. Hannah-Jones N. Choosing a School for my Daughter in a Segregated City. The New York Times Magazine 2016. 
131. Commission on Social Determinants of Health. Closing the gap in a generation: Health equity through action on the social determinants of health. Geneva: World Health Organization; 2008.

132. Hirai AS, Kaufman JS. Fixed versus random effects models for multilevel and longitudinal data. In: Oakes JM, Kaufman JS, editors. Methods in social epidemiology. San Francisco: Jossey-Bass; 2017.

\section{Publisher's Note}

Springer Nature remains neutral with regard to jurisdictional claims in published maps and institutional affiliations.

Ready to submit your research? Choose BMC and benefit from:

- fast, convenient online submission

- thorough peer review by experienced researchers in your field

- rapid publication on acceptance

- support for research data, including large and complex data types

- gold Open Access which fosters wider collaboration and increased citations

- maximum visibility for your research: over $100 \mathrm{M}$ website views per year

At $\mathrm{BMC}$, research is always in progress.

Learn more biomedcentral.com/submissions 